\title{
An approach to aircraft seat comfort using interface pressure mapping
}

\author{
Flavia Renata Dantas Alves Silva Ciaccia ${ }^{\mathrm{a},{ }^{*}}$ and Laerte Idal Sznelwar ${ }^{\mathrm{a}}$ \\ ${ }^{a}$ Department of Production Engineering, School of Engineering-University of São Paulo, Avenida Prof. Almeida \\ Prado, travessa 2, $n^{\circ}$ 128,05508-070 - Cidade Universitária - São Paulo/SP, Brazil.
}

\begin{abstract}
The objective of the present study is to propose a method to dynamically evaluate discomfort of a passenger seat by measuring the interface pressure between the occupant and the seat during the performance of the most common activities of a typical flight ${ }^{1}$. This article reports the results of resting and reading studies performed in a simulator that represents the interior of a commercial aircraft.
\end{abstract}

Keywords: activity analysis, dynamic assessment, aircraft seat

\section{Introduction}

In a competitive market as the aviation industry, one focus of new developments of aircraft interiors has been the passenger comfort. An example is the dimensional label created by the National Civil Aviation Agency (ANAC) that helps passengers to choose an airline according to the living space in economy class. The Brazilian initiative is pioneer and shows that the aviation industry believes that passenger expectations are essential to determine the desired level of quality service.

In recent years the center of attention of many researches has been the identification of objective measures to predict seat comfort. The main objective measurement techniques of seat comfort used in these studies are vibration and muscle activity measurement, pressure interface between the occupant and seat and postural analysis. Some studies also correlate objective measures with subjective data in order to determine their relative effects in the sense of comfort [12]. However, little has been said related to aircraft passengers' seat comfort.

In the passengers' point of view, the most important aspect of an aircraft cabin is the seat, once this is where he will spend most part of the trip [5]. Recent studies show that main problems according to passengers concern legroom, seat width and personal space [26]. In general, people wanted more movement space and possibilities to action [26].

\subsection{Flight, passengers and activities}

Depending on the duration of the flight and whether it is daylight or overnight, the passenger cabin serves as a sitting room, a dining room and even a bedroom [5]. According to Richards et al. (1978), activities with greater degree of difficulty to perform in a typical flight are: sleeping, reading, concentrating, writing and conversation. If the design of a passenger cabin does not consider the main needs of passengers throughout their journey, the result may be an environment which is not suitable to many activities.

Through the understanding of the activities carried out by passengers during flight it is possible to recognize whether a passenger is satisfied or not and their degree of comfort [8]. The analysis of activities performed by passengers allows the identification of the activities that carried out more frequently and

\footnotetext{
* Corresponding author. E-mail: fla_silva@hotmail.com

${ }^{1}$ The presented data were collected in a study entitled "Cabin Comfort - Integrated Analysis and Development of Criteria for Comfort", which has been development through a partnership between Embraer S.A. and Fundação de Amparo a Pesquisa do Estado de São Paulo (FAPESP), having the following universities USP, UFSCar and UFSC as collaborators.
} 
each inherent difficulties and constraints. Based on this information, it is easier to develop comfort solutions that met passengers' needs.

\subsection{Discomfort in sitting posture}

Several studies suggest that pressure distribution has a clear relationship with discomfort during sitting $[4,7,16,17,24]$. According to Looze et al. (2003) a higher pressure resulted in more discomfort. This is because a high surface pressure can compress the blood vessels in tissues, restricting circulation and causing discomfort. Looze et al. (2003) also reported that pressure distribution appears to be the objective measure with the clearest association with the subjective ratings and perhaps that is the technique most widely used to predict seat comfort.

Historically, peak pressure have been used to evaluate seat discomfort; however many authors have conflicting opinions regarding the threshold value. Some studies suggest that threshold value should be $32 \mathrm{mmHg}$ due to its correspondence with the capillary pressure at heart level. Above this pressure the capillaries could be obstructed and it could result in a deprivation of oxygen in the tissues [10, 21, 23]. On the other hand, Bar (1998) determined that this value was too low to be considered as threshold pressure and suggested that a more accurate value for the buttocks would be $60 \mathrm{mmHg}$ [22]. In addition to Bar (1998), other authors also recommend the use of different threshold values according to the body region and the anthropometric group [9, 11, 18, 19].

A recent study performed by Mergl (2006) reinforced the idea that there is not a single value of maximum pressure for the entire seat and not a single parameter of the seat pressure distribution, which may explain the discomfort. Mergl (2006) set guidelines for a car seat good pressure distribution considering three parameters: maximum pressure, percentage of load distribution and gradient of the cumulative curve. The percentage of load distribution is defined by the percentage of the total load on the seat and the load in a particular body region. The gradient of the cumulative curve is described by the resulting curve from the sum of the pressure values in each line from right to left summarized and presented as a 2D curve. According to Mergl (2006), the values of each parameter also vary with the body region exposed to pressure.

Besides the pressure, discomfort is also considered to be related with postural changes in $[6,13,25]$. Liao and Drury (2000) have reported a positive rela- tionship between discomfort and frequency of postural changes analyzing people working with computer. On the other hand, some previous studies did not take into account the fact that sitting is a dynamic task and have mainly focused on postural changes and specific postures [2, 3, 22, 28].

\section{Method}

\subsection{Participants}

This investigation was based on participant observation in which 5 researchers performed the activity of resting or reading in an aircraft passenger seat during 40 minutes while they were being observed by other researcher. Before the beginning of the studies, they were trained to be aware of the limitations of the environment and what led them to change their posture. Three male participants were involved in the study of resting and two males and one female subject participated in the study of reading. The participants' age ranged from 22-30 years old. All experimental procedures were approved by the regional ethics committee (Project "Cabin comfort - Integrated Analysis and Development of Criteria for Comfort- CEP Register: 704/06)".

\subsection{Apparatus}

The experiments were conducted in an aircraft simulator built at the University of São Paulo. The simulator interior reproduces a regional commercial aircraft. The object of study was a passenger seat equipped with two pressure sensors (model X3 PX100: $50.8 \mathrm{~cm} \mathrm{x} 81.28 \mathrm{~cm} 40.64 .02$ - Xsensor), positioned at the backrest and on the bottom cushion. A video camera recorded the movements and postures adopted by the participants throughout the tests.

\subsection{Experimental protocol}

The research was divided into two studies: resting and reading. The main idea was to evaluate how the subjects perform these activities in a simulated environment that represents general aspects of an aircraft cabin as temperature and light condition. The participants of resting and reading studies remained seated for 40 minutes in a double seat equipped with two pressure sensors with no one sitting next to them. The main difference between the studies was the activity that participants must perform during the ex- 
periment. The temperature inside the simulator was set at $21^{\circ} \mathrm{C}$. At the end of 40 minutes, each participant reported their perceptions on the simulation of an activity and described the motivations and intentions that led them to change their posture during the experiment.

\section{Results}

A detailed analysis of resting and reading activities took into account: pressure maps analysis, adopted postures during the experiment and participants' discourse after the experiment.

\subsection{Pressure maps analysis}

By measuring the interface pressure between participant and seat over the 40 minutes of experiment, it was possible to create a pressure map for each posture adopted by him. As the focus of this study was to estimate the advantages of evaluating a seat considering the approach of activity analysis, there was not much concern in investigating the pressure values associated with each posture. Anyway, it was found that in general the values of medium pressure and peak pressure were lower than the recommendation [15].

Observing the graph of pressure versus time, it was simple to identify the exact moment in which the participant modified his posture and consequently how long he remained in the same position. Figure 1 illustrates one example of graph pressure versus time of resting study.

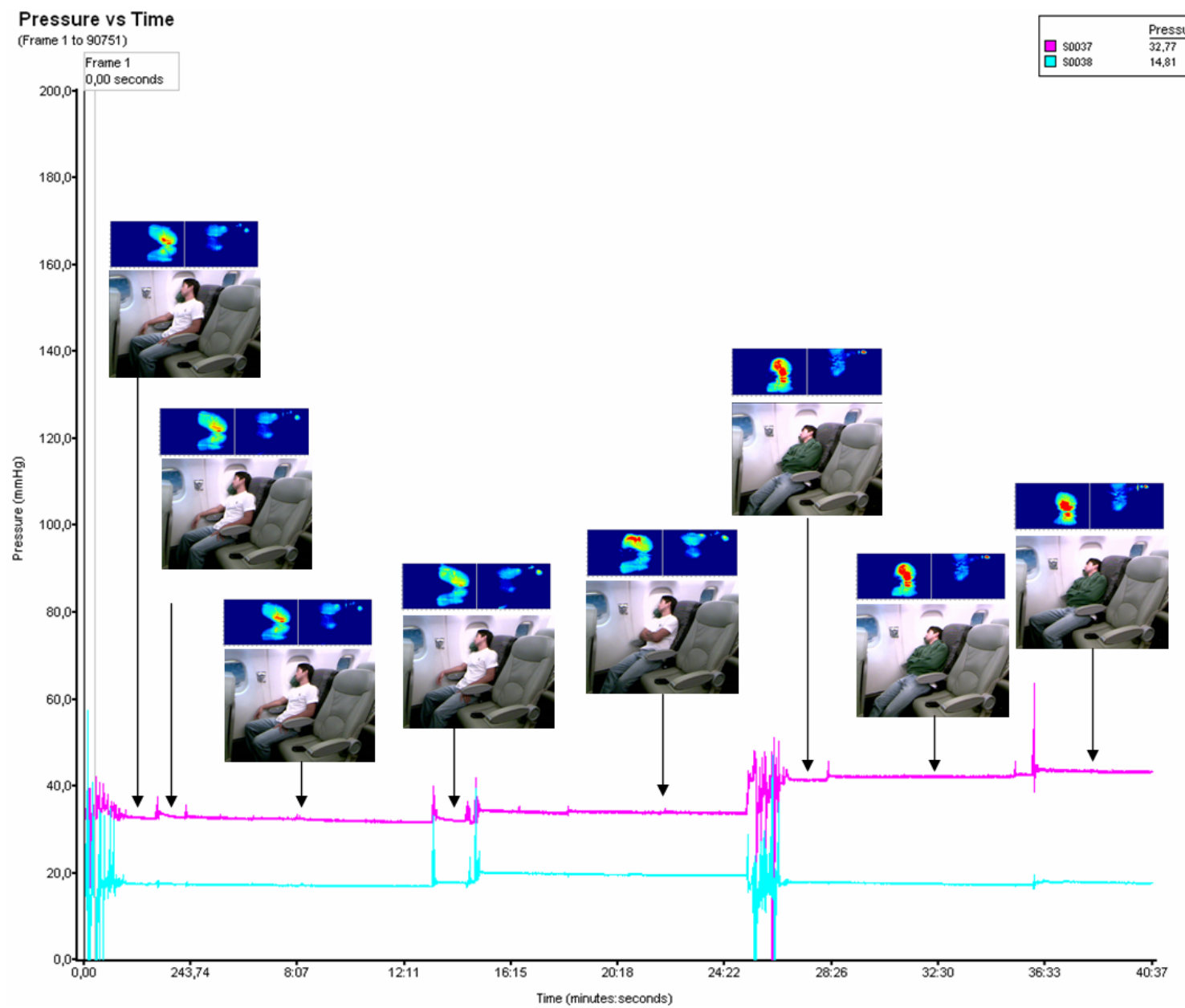

Figure 1 - Pressure versus Time - different postures adopted by second participant of resting study 
The association of pressure map and its corresponding posture taken from the video was essential to identify which alterations occurred over time.

The utilization of a pressure map for each adopted posture highlighted the differences between them over the time. The different postures are related to the support of seat used during the performance of each activity and are only perceived in dynamic evaluations of pressure distribution in which subject's movements are evident.

By overlaying the pressure maps, the contour of the interface area between the subject and the seat is established as shown in Figure 2. This contour can be used to determine which regions of the backrest and bottom cushion are being used and if there are points of excessive concentration of pressure or lack of support.

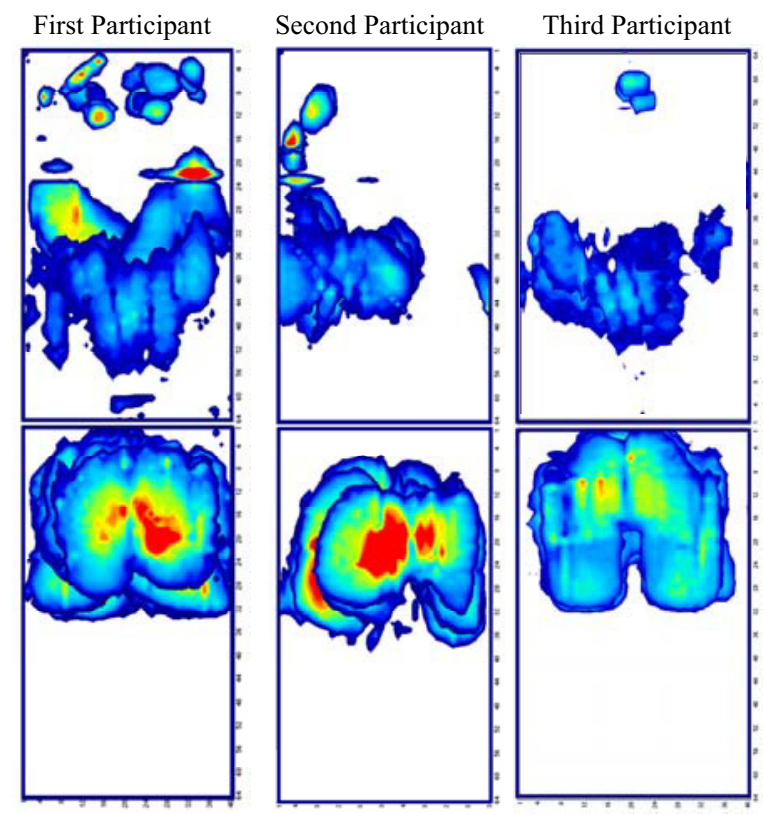

Figure 2 - Overlap of pressure maps of each posture adopted by participants of resting study

\subsection{Postural analysis}

\subsubsection{Resting study}

Starting with the initial position, it was possible to identify some common positions adopted by the participants (Figure 3). In general, they sat with their spine straight and supported on the back of the seat, elbows and feet near body. The only exception was Participant 1 who crossed his legs.



Figure 3 - Participant's initial position of resting study

Over time, participants were settling in the seat and adopting different postures of head, legs and pelvis. A common fact that happens few minutes after the beginning of the experiment was the modification to backward leaning posture. Although Wilke et al. (1999) affirmed that this posture reduces the load on the lumbar back, observe in the pressure maps in Figure 4 that the buttocks and neck region are overloaded and lumbar support is reduced. Interestingly, this posture in these cases is also associated with the presence of legs outstretched.

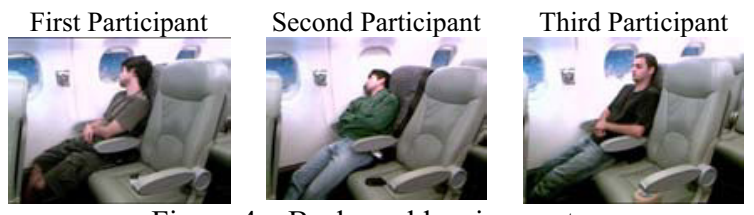

Figure 4-Backward leaning posture

It was also observed that the participants frequently turned their head and neck during the experiment looking for a support in the window, in the seat next him or in the hand, as can be seen in Figure 5. Although repeat all over the resting study, the search for an effective support to the head and neck was tiring. One common strategy used by most participants was to switch the hand that support the head between right and left.



Figure 5 - Different head position - resting experiment

An interesting fact observed was the massive use of the armrests. Most of the time the participants supported the elbow in at least one of them, but there were some attempts to support the entire forearm. Of course, it is important to notice that the protocol of the experiment encouraged the use of the armrests because there was nobody sitting next participants. 
Figure 9 illustrates some arm and forearm postures adopted by the participants.

\subsubsection{Reading study}

Once again there was some uniformity in the adopted posture of the participants. In their first posture they supported their backs on the backrest, used the armrests and positioned the head forward toward the book that was held by their hands, as can be seen at Figure 6. After a while in this position, the participants brought the book closer to the face, supporting the head and shoulder in the backrest. However, this posture did not take so long because the book weight forced a search for a new support for it. One alternative was to support the book on their thighs. As in resting study, the armrests were also widely used.
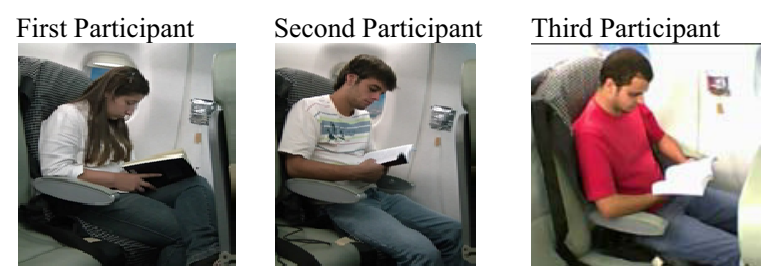

Figure 6 - Participants initial position of reading study

It was verified that the participants not only have adopted various solutions to support their head and book during the reading but also assumed different leg positions.

\subsection{Passenger's discourse}

Each participant had a different frequency of movement during the experiment independently of the study. These differences can be related to several factors, among them, engaging in the activity and degree of discomfort. The report of the participants after the experiment was crucial to understanding both the degree of engagement in the activity and discomfort in each adopted posture. For example, the description from the second participant of resting study showed that he really slept and that for him he had been in only two positions. In fact, the postural and pressure map analysis identified two major postures with some small variations in his legs. According to the second participant, these small variations were a strategy to avoid the tingling in his legs.

The same occurred in the reading study. According to the fourth participant, she was tired and had to move several times not to sleep. Moreover, she changed the way of holding the book due to discom- fort in her hands and neck. The book was heavy and she preferred to support it in her thighs, but in this position the book remained out of her line of sight forcing her neck forward. The same happened with her legs, which were crossed from one side to another in search of a better position.

\section{Conclusions}

Activity analysis in combination with the pressure mapping evaluation goes beyond the static analysis currently used for measuring comfort of aircraft passenger seats. In addition to objective data such as average and maximum pressure in each adopted posture, the proposed method identifies some strategies used by participants to minimize a state of discomfort. This could not be perceived in static experiments or short-term evaluations. Another point to be considered is that the perception of participants after the experiment was crucial to interpret the videos and analyze the postural changes. The previous training of participants made it easier to identification their discomforts and strategies taken to avoid them. The speech of the participants demonstrated the intention and motivation that led them to frequently change their posture throughout the experiment. In addition, their perceptions also helped identify areas of improvement in the design of the seat and point out the positive aspects of it.

Despite having different anthropometric characteristics, the participants adopted very similar postures, strategies and body positions in order to avoid the discomfort. Furthermore, part of the results would not have been raised if the experiment had not been conducted in a representative environment of an aircraft interior. Many times during the experiments, the participants used some elements of the environment such as windows, and side ledge to support mainly their heads and limbs.

\section{References}

[1] Bar, C. Pressure: Why measure it and how. A presentation at the 14th International Seating Symposium. Vancouver, BC, 1998.

[2] Branton, P., Grayson, G. An evaluation of train seats by observation of sitting behaviour. Ergonomics 10, 35, 1967.

[3] Dempster,W.T The anthropometry of body action. Annals of the New York Academy of Sciences 63, 559-585, 1955

[4] Dhingra, H.S.; Tewari, V.K.; Singh, S. Discomfort, Pressure Distribution and Safety in Operator's Seat - A Critical Review 
Agricultural Engineering International: the CIGR Journal of Scientific Research and Development. v. V, 2003.

[5] Edwards, M.; Edwards, E. The Aircraft Cabin. Aldershot, UK. Gower Publishing Company Ltd, 1990.

[6] Fenety, A., Walker, J.M. Shortterm effects of workstation exercises on musculoskeletal discomfort and postural changes in seated video display unit workers. Physical Therapy 82 , 578-589, 2002.

[7] Goonetilleke, R.S.; Feizhou, S. A methodology to determine the optimum seat depth. International Journal of Industrial Ergonomics, Hong Kong, 27, pp 207-217, 2001.

[8] Jacobson, D.I.; Martinez,J. The comfort and satisfaction of air travelers-basis for a descriptive model. Human Factors, v.16, n.1, p.46-55, 1974.

[9] Kamijo, K., Tujimura, H., Obara, H., Katsumata, M., 1982. Evaluation of Seating Comfort. SAE Technical Papzer Series 820761.

[10]Kärki, S.; Lekkala, J. Pressure mapping system for physiological measurements. In: XVIII Imeco world congress Metrology for a Sustainable Development, Rio de Janeiro, 2006.

[11]Kolich, M. Predicting automobile seat comfort using a neural network. International Journal of Industrial Ergonomics 33,p. 285-293, 2004

[12]Kolich, M. Review: A conceptual framework proposed to formalize the scientific investigation of automobile seat comfort. Applied Ergonomics, vol. 39, no. 1, pp. 15-27, 2008.

[13]Liao, M.H., Drury, C.G. Posture, discomfort and performance in a VDT task. Ergonomics 43, 345-359, 2000.

[14]de Looze, M.P., Kuijt-Evers, L.F.M.; van Diee“N, J. Sitting comfort and discomfort and the relationship with objective measures. Ergonomics, v.46, p.985 - 997, 2003.

[15] Mergl, C. Entwicklung eines verfahrens zur optimierung des sitzkomforts auf Automobilsitzen. PhD.dissertation.Technical University München, 2006.

[16]Moes, N.C.C.M. Pressure Distribution and Ergonomics Shape Conceitualization. In:International Design Conference, Dubrovnik, 2000.

[17]Noro, K. Fujimaki, G.; Kishi, S. A theory on pressure distribution and seat discomfort. In VINK, P. Comfort and design: principles and good practice. Florida, CRC Press, 2005.
[18] Oudenhuijzen, A.; Tan, K.; Morsch, F. The Relationship Between Seat Pressure and Comfort. SAE Technical Paper n. 2003-01-2213, 2003.

[19] Peterson, M.J; Adkins, H.V. Measurement and Redistribution of excessive pressures during wheelchair sitting - a clinical report, Physical Therapy, v.62, n.7, July 1982.

[20]Richards, L.G.; Jacobson, I.D.; Kuhlthau, A.R. What the passenger contributes to passenger comfort. Applied Ergonomics, v.9, n.3, p.137-142, 1978 .

[21] Shelton, F.; Lott, J.W. Conducting and Interpreting Interface Pressure Evaluations of Clinical Support Surfaces, Geriatric Nursing, v. 24, n. 4, p.222-227, 2003.

[22] Souza, A.D.C.K. Análise da distribuição de pressão em poltronas aeronáuticas utilizando um mecanismo de reclinação conjunta. Master Thesis. Instituto Tecnológico de Aeronáutica, São José dos Campos, Brasil. 2009.

[23] Stinson,M.D.; Porter-Armstrong, A.; AKIN, P. Seat-Interface Pressure: A Pilot Study of the Relationship of to Gender, Body Mass Index, and Seating Position. Archives of Physical Medicine and Rehabilitation, v. 84, n. 3, 2003.

[24] Stumpf, B.; Chadwick, D.; Dowell, B. A arte da distribuição da pressão: critérios ergonômicos para o design da Aeron Chair, 2002. Disponível em: $<$ http://www.atecnet.com.br/download/produtos/Aeron/ergono mia/03_aeron_ergo_pressure.pdf> Acesso em: 06/072011 às $13: 24$.

[25] Vergara, M., Page, A. Relationship between comfort and back posture and mobility in sitting-posture. Applied Ergonomics 33, 1-8, 2002.

[26]Vink; P.; Kamp, I.; Blok, M. Aircarft Interior Comfort Experience. Delft University of Technolgy/Faculty Industrial Design Engineering, 2005.

[27] Wilke, H.J., Neef, P.; Caimi, M.; Hoogland, T.; Claes, LE. New in vivo measuremts of pressures in the intervertebral disc in daily life. Spine, v. 24, n. 8, p.755-762, 1999.

[28] Yoshida, M. M. Estudo de parâmetros de conforto de poltronas de aeronaves executivas. Dissertação (Mestrado Engenharia Aeronáutica e Mecânica). Instituto Tecnológico de Aeronáutica, São José dos Campos, Brasil. 2009. 